\title{
Preclinical evaluation of the AR inhibitor enzalutamide in triple-negative breast cancer cells
}

\author{
Francesco Caiazza1,2,*, Alyson Murray1,*, Stephen F Madden³, Naoise C Synnott1, \\ Elizabeth J Ryan'1,2, Norma O’Donovan4, John Crown'1,5 and Michael J Duffy',6 \\ 1School of Medicine, University College Dublin, Ireland \\ ${ }^{2}$ Centre for Colorectal Disease, St. Vincent's University Hospital, Dublin, Ireland \\ 3Population Health Sciences, Department of Psychology, Royal College of Surgeons in Ireland, Dublin, Ireland \\ ${ }^{4}$ National Institute for Cellular Biotechnology (NICB), Dublin City University, Dublin, Ireland \\ ${ }^{5}$ Department of Medical Oncology, St. Vincent's University Hospital, Dublin, Ireland \\ ${ }^{6}$ UCD Clinical Research Centre, St. Vincent's University Hospital, Dublin, Ireland \\ *(F Caiazza and A Murray contributed equally to this work)
}

Correspondence

should be addressed

to F Caiazza

Email

francesco.caiazza@gmail.com

\begin{abstract}
The androgen receptor (AR) is present in approximately $80 \%$ of invasive breast cancer patients and in up to $30 \%$ of patients with triple-negative breast cancer (TNBC).

Therefore, our aim was to investigate the targeting of AR as a possible hormonal approach to the treatment of TNBC. Analysis of 2091 patients revealed an association between AR expression and poor overall survival, selectively in patients with the basal subtype of breast cancer, the vast majority of which are TNBC. IC ${ }_{50}$ values for the secondgeneration anti-androgen enzalutamide across 11 breast cancer cell lines varied from $4 \mu \mathrm{M}$ to $>50 \mu \mathrm{M}$. The activity of enzalutamide was similar in TN and non-TN cell lines but was dependent on the presence of AR. Enzalutamide reduced clonogenic potential and cell growth in a 3D matrix in AR-positive cells. In addition, enzalutamide also inhibited cell migration and invasion in an AR-dependent manner. Enzalutamide appeared to mediate these processes through down-regulation of the transcription factors AP-1 and SP-1. The first-generation anti-androgen flutamide similarly blocked cell growth, migration and invasion. AR-positive TNBC cells clustered separately from AR-negative cells based on an androgen-related gene expression signature, independently of TNBC subtype. We conclude that targeting of the AR with drugs such as enzalutamide may provide an alternative treatment strategy for patients with AR-positive TNBC.
\end{abstract}

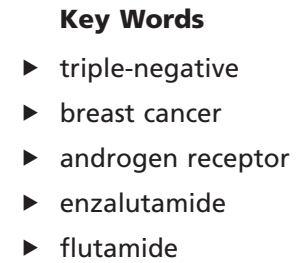

Endocrine-Related Cancer (2016) 23, 323-334

\section{Introduction}

Breast and prostate cancers depend on steroid hormones to drive their growth: oestrogens drive the growth of breast cancers, whereas androgens stimulate the growth of prostate cancers. Consequently, antioestrogens are used to treat breast cancer and anti- androgens to treat prostate cancer (Risbridger et al. 2010). However, a proportion of breast cancers contains androgen receptors (AR) (Qu et al. 2013, Vera-Badillo et al. 2014) and may thus be dependent on androgens.

Published by Bioscientifica Ltd 
Although the presence of AR in breast cancer has been known for decades, it has not been widely investigated as a potential therapeutic target in this malignancy. This situation, however, is now changing, especially for the subgroup of breast cancer patients that lack oestrogen receptors (ER), progesterone receptors (PR) and HER2, i.e. those with triple-negative breast cancer (TNBC) (recently reviewed in Shah et al. 2013, Safarpour \& Tavassoli 2014, Proverbs-Singh et al. 2015). Because of the absence of these three predictive biomarkers, TNBC currently lacks a validated targeted therapy (Duffy et al. 2012). Although lacking ER, PR and HER2, approximately $22-45 \%$ of TNBC express AR (Gucalp \& Traina 2010, Park et al. 2010, Collins et al. 2011, Kotsopoulos \& Narod 2012, McNamara et al. 2013, Gasparini et al. 2014, Safarpour \& Tavassoli 2014, Barton et al. 2015).

Gene expression analysis of patient samples has been used to identify different molecular subtypes of TNBC, including one characterized by androgen receptor signalling and named luminal androgen receptor (LAR) (Lehmann et al. 2011), which is closely related to a molecular apocrine breast cancer subtype previously identified (Farmer et al. 2005, Doane et al. 2006). Indeed, at least two clinical trials targeting the AR in patients with TNBC are currently ongoing (Gucalp et al. 2013 and ClinicalTrials.gov Identifier: NCT01889238). Despite these ongoing clinical trials, little detailed preclinical work targeting AR in triple-negative (TN) cell lines has been performed. Therefore, the aim of this study was to investigate the potential of targeting the AR in a large panel of breast cancer cells, focusing particularly on those that possess the TN phenotype. For targeting AR, we used two clinically available anti-androgens: the first-generation agent, flutamide, and the second-generation agent, enzalutamide.

\section{Material and methods}

\section{Cell lines and reagents}

HCC1937, HCC1143, Hs578t, BT-20, MDA-MB-231, MDA-MB-453, MDA-MB-468, Sum-159, Cama1, T47D and BT474 cells were obtained from the American Tissue Culture Collection. Hs578t cells were supplied by Dr Susan McDonnell (University College Dublin, Ireland). LnCap cell lysates, used as a positive control for AR, were a gift from Dr Maria Prencipe (University College Dublin). All cell lines were grown in RPMI-1640, supplemented with $10 \%$ foetal bovine serum, $1 \%$ penicillin/streptomycin and 1\% fungizone (all from Invitrogen Life Technologies, Carlsbad, CA, USA) and used for experiments between passages 3 and 15 from original stocks. Cell line identity was confirmed by analysis of short-term repeat loci, and cells were routinely tested for mycoplasma infection. The molecular characteristics of the cell lines investigated are summarised in Table 1. Flutamide was purchased from Sigma Aldrich (Arklow, Ireland) and enzalutamide from SelleckChem (Munich, Germany).

\section{Protein isolation, immunoblotting and ELISA}

Cells were lysed in RIPA buffer $(150 \mathrm{mM} \mathrm{NaCl}, 50 \mathrm{mM}$ Tris-HCl, $1 \%$ Triton, $0.5 \%$ sodium deoxycholate, and $0.1 \%$ SDS) supplemented with a protease and phosphatase inhibitor cocktail (Roche Applied Science, Burgess

Table 1 Pathological and molecular profiles of breast cancer cell lines.

\begin{tabular}{|c|c|c|c|c|c|c|c|}
\hline & ER & PR & HER2 & PAM50a & Intrinsic subtype ${ }^{b}$ & TNBC subtype & Normal-cell subtype \\
\hline HCC1937 & - & - & - & Basal A & Basal & BL1 & HR1 \\
\hline HCC1143 & - & - & - & Basal A & Basal & BL1 & - \\
\hline BT20 & - & - & - & Basal A & Basal & uncl & HR1 \\
\hline MDA-MB-468 & - & - & - & Basal A & Basal & BL1 & HR1 \\
\hline MDA-MB-231 & - & - & - & Basal B & Normal-like & MSL & - \\
\hline Hs578t & - & - & - & Basal B & Normal-like & MSL & - \\
\hline SUM159 & - & - & - & Basal B & Normal-like & MSL & HR1 \\
\hline MDA-MB-453 & - & - & $-[+] *$ & Luminal & HER2+ & LAR & HR2 \\
\hline Cama1 & + & - & - & Luminal & Luminal & - & - \\
\hline T47D & + & + & - & Luminal & Luminal & - & HR3 \\
\hline ВT474 & + & + & $+[+]$ & Luminal & HER2+ & - & HR3 \\
\hline
\end{tabular}

Protein expression of oestrogen receptor (ER), progesterone receptor (PR) and HER2 were derived from Kao et al. (2009) and Neve et al. (2006); HER2 gene amplification is reported in square brackets (*MDA-MB-453 have HER2 amplification without overexpression). Classification of cell lines to breast cancer subtypes by nearest centroid correlation based on different gene expression signatures: aPAM50 (Parker et al. 2009), bssp2003 (Sorlie et al. 2003), cTNBC (Lehmann et al. 2011). dClassification according to normal cell type-based ontological method (Santagata et al. 2014). BL1, basal-like 1; MSL, mesenchymal stem-like; LAR, luminal androgen receptor; HR1-2-3: hormonal differentiation groups. 


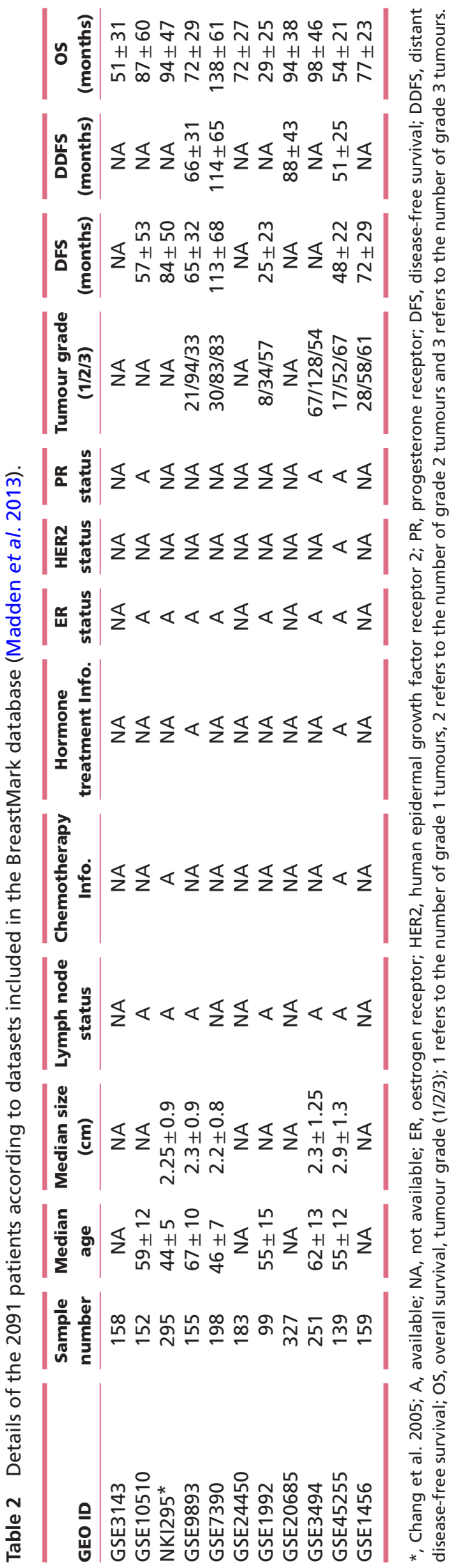

http://erc.endocrinology-journals.org DOI: 10.1530/ERC-16-0068
() 2016 Society for Endocrinology Printed in Great Britain
Hill, UK) and $1 \mathrm{mM}$ PMSF (Sigma Aldrich). Western blot was performed as described previously (Caiazza et al. 2015) using a mouse monoclonal antibody for AR (clone 441; Santa Cruz Biotechnology, Heidelberg, Germany), with normalization against $\beta$-actin (Sigma Aldrich). AR levels were quantified with an ELISA assay (Abcam, Cambridge, UK) following manufacturer's instructions and using a LnCap cell lysate as positive control.

\section{Clonogenic assays}

Colony formation assays were performed as described previously (Caiazza et al. 2015). Image analysis was performed using ImageJ software (NIH, Bethesda, MA, USA; http://imagej.nih.gov/ij/) to determine colony size and area (Cai et al. 2011). Plating efficiency was calculated by dividing the number of colonies by the original seeding density. The surviving fraction was determined by comparing the plating efficiency of treated vs control wells. The total colony area was calculated for each biological replicate by averaging the area of all colonies in replicate wells.

\section{Cell invasion assays}

Cell motility was assessed as described previously (Caiazza et al. 2015) using Matrigel-coated inserts (8- $\mu \mathrm{m}$ pore size; BioCoat, BD Biosciences, Erembodegem-Dorp, Belgium) or non-Matrigel-coated control inserts and fibroblastconditioned medium as chemoattractant.

\section{Three-dimensional cell culture}

For 3D cultures, $5 \times 10^{5}$ cells were seeded in Alvetex scaffolds (Reinnervate, Sedgefield, Co. Durham, UK) in low serum (2\%) medium and cultured for 7 days. At the end of the incubation, scaffolds were washed in PBS and stained with a $0.25 \%$ solution of neutral red (Sigma Aldrich) in PBS for $5 \mathrm{~min}$ at room temperature. Scaffolds were imaged on a bright field microscope at $4 \times$ magnification, averaging four random fields for each scaffold. A $1 \times$ magnification image of the entire scaffold was acquired with a standard digital camera. Neutral red staining was quantified with ImageJ software.

\section{RT2 profiler PCR array analysis}

Total RNA isolated using the RNeasy Mini kit (Qiagen, Manchester, UK) was transcribed into cDNA using the RT2 First-strand Kit (Qiagen). The cDNA ( $0.5 \mu \mathrm{g}$ of template) was used on the real-time Human Androgen Receptor

Published by Bioscientifica Ltd. 
A

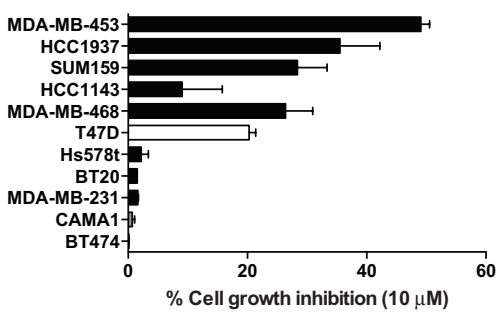

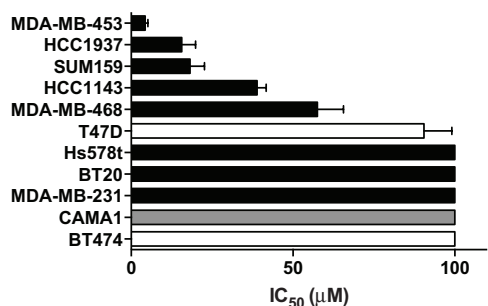

B

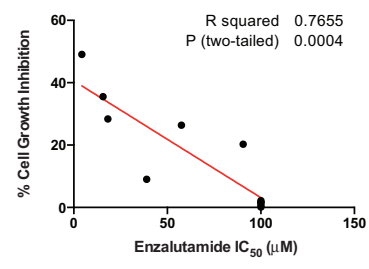

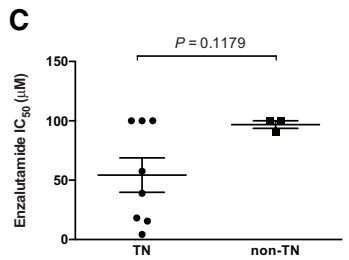

D
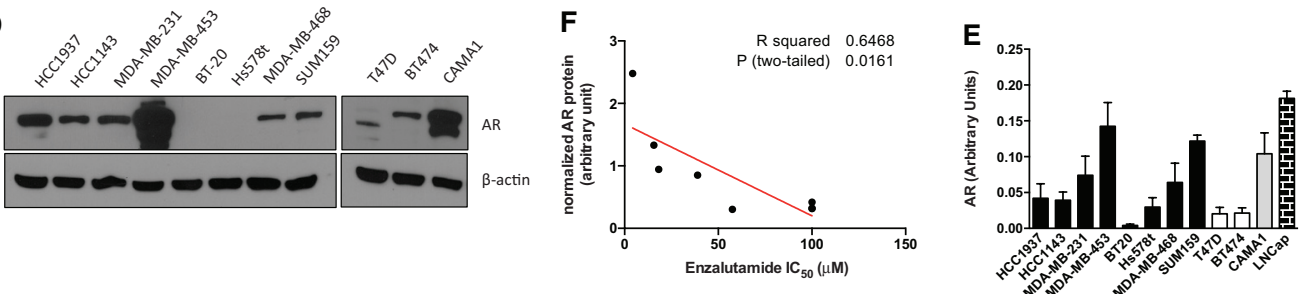

Figure 1

Effect of enzalutamide in breast cancer cells is related to AR protein expression. (A) Colony formation was measured for 11 cell lines in the presence of different concentrations of enzalutamide $(0.05-100 \mu \mathrm{M})$. Bar charts indicate the percentage inhibition of cell growth after treatment with $10 \mu \mathrm{M}$ enzalutamide and the corresponding $I_{50}$ values for all cell lines. Black bars $=T N B C$, grey bars $=$ HER $2+$, white bars $=$ luminal breast cancer cell lines. (B) Bivariate scattergram illustrating the direct negative correlation between $\mathrm{IC}_{50}$ values and percentage growth inhibition following treatment with $10 \mu \mathrm{M}$ enzalutamide. Data was analysed using the Pearson correlation test. (C) IC $\mathrm{C}_{50}$ values for enzalutamide were compared in TN cells $(n=8)$ vs non-TN cells $(n=3)$. (D and E) Western blot and ELISA analysis for the AR was performed on total cell lysates from the indicated cell lines. The prostate cancer cell line LnCap was used as a positive control. (F) Bivariate scattergram illustrating the direct negative correlation between $I_{50}$ values for enzalutamide and $A R$ protein expression in TN cells. A full colour version of this figure is available at http://dx.doi.org/10.1530/ERC-16-0068.

Signaling Targets RT2 Profiler PCR Array (Qiagen) in combination with $\mathrm{RT}^{2}$ SYBR Green qPCR Mastermix. Cycle threshold $\left(C_{t}\right)$ values were normalized using three housekeeping genes and analysed using the data analysis web portal (http://www.qiagen.com/geneglobe) following manufacturer's instructions. The fold change gene expression was calculated with the delta $C_{t}$ method. Confirmatory RT-PCR analysis of FOS and JUN mRNA was performed in triplicate using the RT ${ }^{2}$ qPCR Primer Assay (Qiagen) and GAPDH as housekeeping gene.

\section{Hierarchical clustering of breast cancer cells}

A gene signature for the LAR subtype of TNBC was derived from two publicly available datasets describing $\mathrm{ER}^{-} / \mathrm{AR}^{+}$ breast cancer, based on the analysis of 41 (Doane et al. 2006) and 49 (Farmer et al. 2005) patients. The list of the 100 genes most differentially expressed in the ER- class A tumours from the Doane cohort was compared with the list of genes that discriminate for group 3 (molecular apocrine) in the Farmer cohort. The resulting list of 76 genes commonly discriminating both groups of LAR patients is reported in Supplementary Table 1 (see section on supplementary data given at the end of this article). This 76 gene list was used to perform unsupervised hierarchical clustering of a publicly available breast cancer cell line dataset (Neve et al. 2006) containing all 11 cell lines of our original panel. To cluster data, we used CIMiner software (http://discover.nci.nih.gov/cimminer/home.do) (Weinstein et al. 1997) with the Euclidean distance method; the average linkage was used as the measure of proximity between clusters to construct dendrograms.

\section{Mining of publicly available breast cancer microarray data}

Analysis of breast cancer datasets was carried out using BreastMark (Madden et al. 2013). Kaplan-Meier survival curves were generated at http://glados.ucd.ie/BreastMark/ index.html. The key characteristics of the different cohorts of patients in this database are summarised in Table 2 .

\section{Statistical analysis}

Statistical analysis of the data was performed with paired Student's $t$-test or one-way ANOVA for differences 


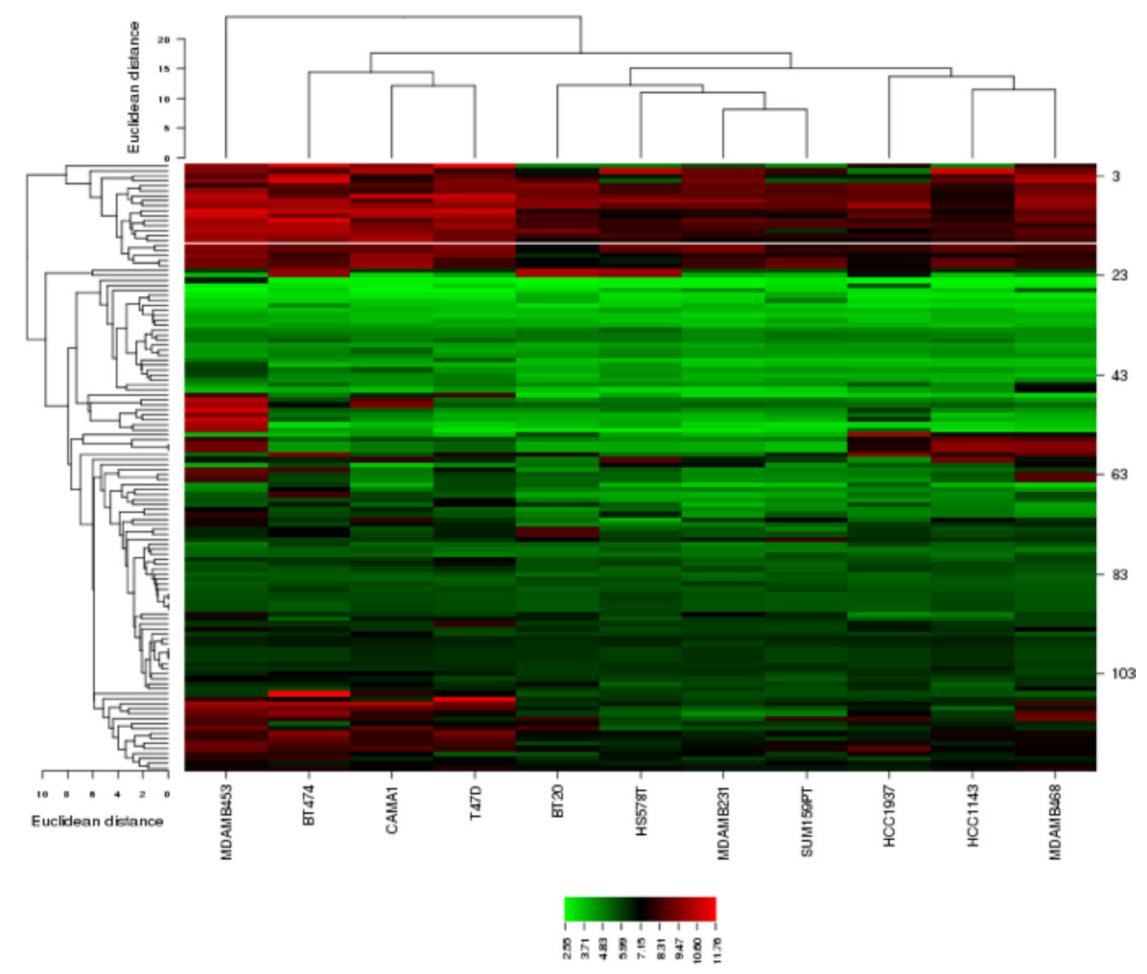

\section{Figure 2}

Molecular clustering of breast cancer cell lines. Hierarchical clustering was performed on 11 breast cancer cells based on the 76 genes signature of LAR subtype. The dendrogram represents the relationship among samples, with the length of branches representing the correlation coefficient between samples. Cell lines are arranged in columns and genes are arranged in rows. Gene expression levels are pseudocolored according to the legend reported at the bottom of the figure. A full colour version of this figure is available at http://dx.doi. org/10.1530/ERC-16-0068. between experimental group mean values. Pearson's coefficient was used to measure the correlation between linear variables. Survival curves were calculated according to the Kaplan-Meier method and compared using the Cox-Mantel log-rank test. The AR expression was categorised as high or low using the 'low' cut-off point from BreastMark (Madden et al. 2013), and overall survival (OS) was chosen as the survival endpoint. Two-tailed $P$-values $<0.05$ were considered statistically significant. All analyses were performed using Prism 5 (Graphpad Software, La Jolla, CA, USA).

\section{Results}

\section{Effect of enzalutamide on growth of breast cancer cells}

The effect of enzalutamide on clonogenic growth of 11 breast cancer cell lines (eight TNBC and three non-TN) is summarised in Fig. 1A. Sensitivity to enzalutamide treatment was widely variable, with $\mathrm{IC}_{50}$ values ranging from $4 \mu \mathrm{M}$ to $>50 \mu \mathrm{M}$. The percentage of cell growth inhibition at $10 \mu \mathrm{M}$ varied from $0 \%$ to $49 \%$, with the highest inhibition seen in MDA-MB-453 and HCC1937 cells. Overall, a strong and significant correlation was found between the $\mathrm{IC}_{50}$ values for enzalutamide and percentage growth inhibition $\left(r=-0.8749, P=4.00 \times 10^{-4}\right.$; Fig. 1B). The cell lines found to be most sensitive to enzalutamide were MDA-MB-453 and HCC1937, both of which are TN. Overall, however, the response to enzalutamide was cell line dependent and unrelated to whether cell lines were TN or non-TN ( $P=0.118$; Fig. 1C). Western blot and ELISA analysis of the AR expression by 11 BC cell lines (Fig. 1D and E respectively) revealed a significant correlation between the level of AR protein expression and sensitivity to enzalutamide selectively in TN cells ( $r=-0.804, P=0.016$; Fig. $1 F)$.

\section{Characterization of AR-positive TNBC cells}

In order to verify that the cell line models we used were representative of AR-positive TNBC, we selected a 76-gene signature from genes highly deregulated in LAR TNBC patients (Farmer et al. 2005, Doane et al. 2006) and used it to perform hierarchical clustering of the 11 BC cell lines (Fig. 2). MDA-MB-453 was the cell line most representative of the LAR subtype, as previously reported, and it closely clustered with luminal cell lines. The AR-positive cells HCC1937, HCC1143 and MDA-MB-468 clustered together, whereas the AR-negative cells BT20, Hs578t and MDA-MB-231 were the least representative of the LAR subtype. The only exception to this was SUM159, which clustered with the AR-negative cells despite showing AR expression.

Published by Bioscientifica Ltd 
A

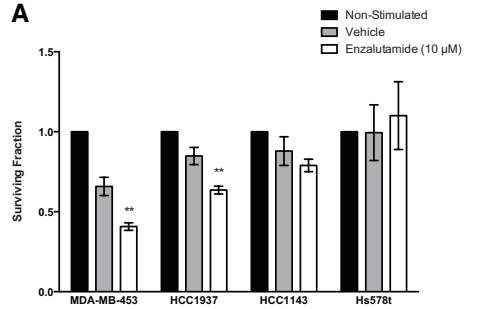

B

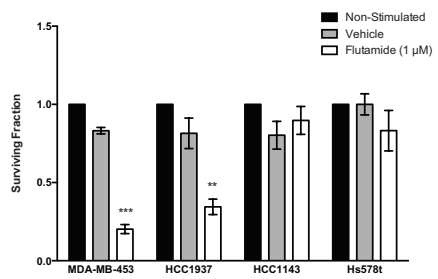

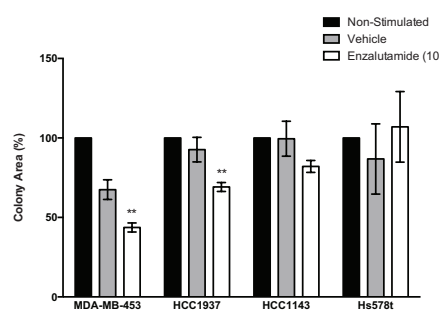

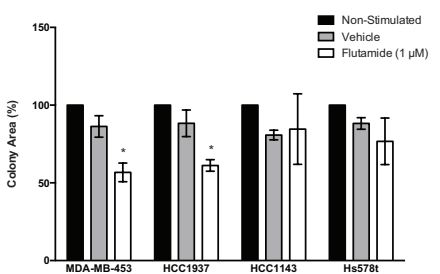

C

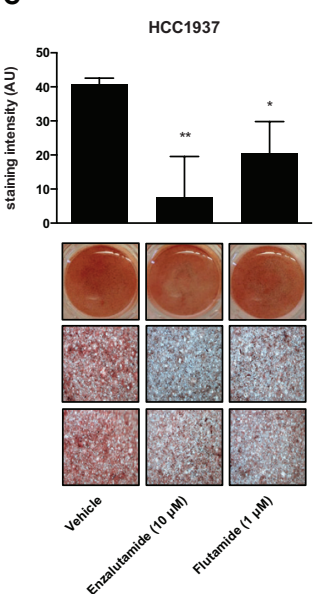

D

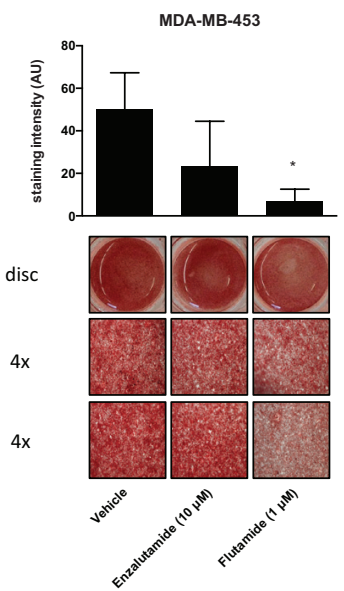

Figure 3

Growth inhibitory effect of AR inhibition in TNBC cells. (A and B) Colony formation was measured for the indicated four cell lines in the presence of (A) enzalutamide $(10 \mu \mathrm{M})$ or $(B)$ flutamide $(1 \mu \mathrm{M})$. Bar charts indicate the surviving fraction and mean colony area for each compound. (C) HCC1937 or (D) MDA-MB-453 cells were cultured for 7 days on 3D scaffolds in the presence of flutamide $(1 \mu \mathrm{M})$ or enzalutamide $(10 \mu \mathrm{M})$. Neutral red staining was quantified and reported with representative pictures. Data are mean values \pm S.E.M. of three independent experiments. ${ }^{*} P<0.05,{ }^{*} * P<0.001$,

$* * * P<0.0001$ compared with vehicle control (ANOVA). A full colour version of this figure is available at http://dx.doi.org/10.1530/ERC-16-0068.

\section{Effect of enzalutamide on growth of TNBC cells}

As our primary interest was to develop an alternative treatment strategy for TNBC, our subsequent in vitro investigations focused exclusively on AR-positive cells of this molecular subtype (MDA-MB-453, HCC1937 and HCC1143) as well as the AR-negative cell line, Hs578t, as control. As shown in Fig. 3A, enzalutamide reduced clonogenic potential as measured by both decreased number of colonies and mean colony area in the two cell lines expressing high levels of AR, i.e. in MDA-MB-453 and HCC1937 cells. In contrast, there was little (nonsignificant) effect on growth in the cell line with low AR expression (HCC1143 cells) and no detectable changes in the AR-negative cell line Hs578t. Similar to our findings with enzalutamide, the first-generation antiandrogen flutamide also decreased clonogenic growth in an AR-dependent manner (Fig. 3B). Although both AR antagonists were investigated in only four cell lines, there was a high correlation between the $\mathrm{IC}_{50}$ values for the two inhibitors $(r=0.9722, P=0.028)$. Enzalutamide also reduced clonogenic potential in two other TN cell lines showing detectable but low AR expression, MDA-MB-468 and SUM159 (Fig. 4A and B).

In order to confirm our findings in a more biologically relevant system, we investigated the anti-growth effects of enzalutamide in AR-positive cells cultured in 3D scaffolds (Fig. 3C and D). Using this system, the effect of the two inhibitors was cell line-specific, with both flutamide and enzalutamide reducing the growth of HCC1937 cells (Fig. 3C), whereas only flutamide significantly reduced growth of MDA-MB-453 cells (Fig. 3D). There was, however, a non-significant trend for enzalutamide to reduce growth in MDA-MB-453 cells $(P=0.169)$. In contrast, enzalutamide showed no effect on the three-dimensional growth of the AR-negative cell line Hs578t or the low AR-expressing cell line MDA-MB-468 (Fig. 4C and D).

\section{Transcriptional effects of enzalutamide in TNBC cells}

In order to clarify the mechanism by which enzalutamide reduced cell proliferation in AR-positive cells, we investigated the effects of the anti-androgen on gene expression in the MDA-MB-453 cell line. Using a threshold of fold change in gene expression of two, five genes were found to be significantly down-regulated following treatment with enzalutamide (Table 3). Among these genes were FOS and JUN, which are known to heterodimerize and form the transcription factor AP-1 (Vesely et al. 2009).

AP-1 has previously been implicated in a variety of cellular processes, including proliferation and migration (Vesely et al. 2009), as well as being linked to enhanced AR transactivation in prostate cancer cells (Chen et al. 2006). Therefore, we validated the FOS and JUN array

Published by Bioscientifica Ltd 
A

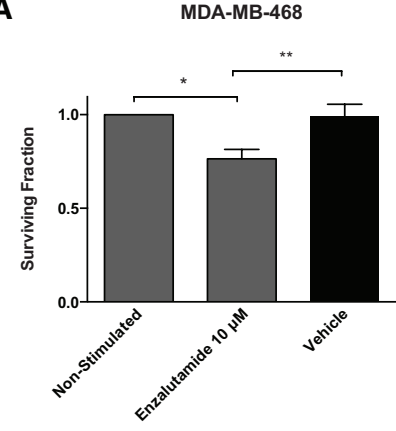

B

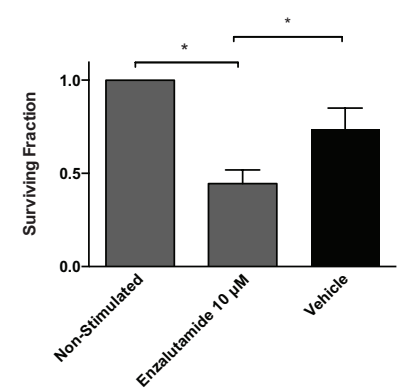

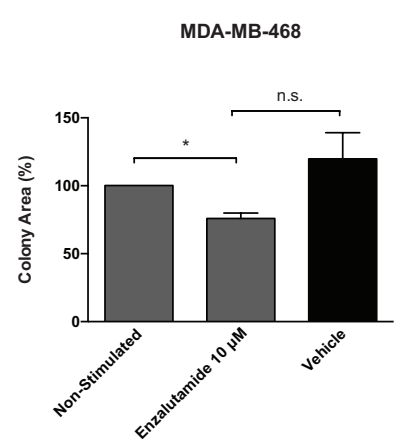

SUM159

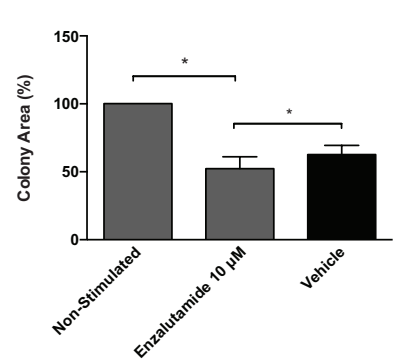

C

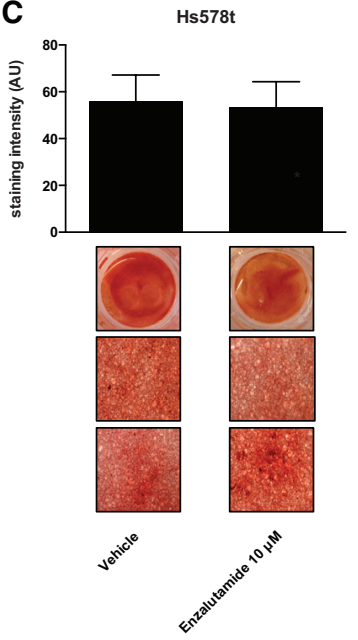

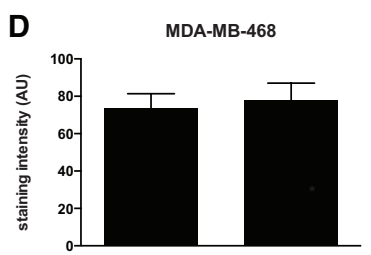

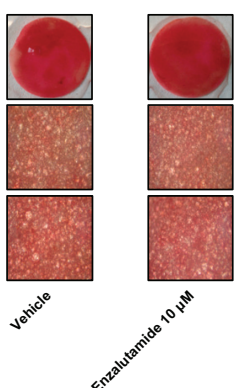

Figure 4

Growth inhibitory effect of AR inhibition in additional TNBC cells. Colony formation was measured for (A) MDA-MB-468 and (B) SUM159 in the presence of enzalutamide $(10 \mu \mathrm{M})$. Bar charts indicate the surviving fraction and mean colony area for each compound. (C) Hs578t or (D) MDA-MB-468 cells were cultured for 7 days on $3 \mathrm{D}$ scaffolds in the presence of enzalutamide $(10 \mu \mathrm{M})$. Neutral red staining was quantified and reported with representative pictures. ${ }^{*} P<0.05, * * P<0.001$. A full colour version of this figure is available at http://dx.doi.org/10.1530/ERC-16-0068.

results by RT-PCR. Treatment of the AR-positive cell line, MDA-MB-453, with enzalutamide was found to reduce expression of FOS and JUN by 2.6- and 1.7-fold respectively (Fig. 5A). In contrast, enzalutamide had no effect on the expression of these two genes in the AR-negative cell line, BT-20 (Fig. 5B).

\section{Effect of AR inhibition on TNBC cell motility}

As most TNBC have a basal phenotype and are highly invasive, we next examined whether AR inhibition impacted on their invasive potential. As shown in Fig. 6, enzalutamide reduced cell migration and invasion in the three AR-positive cell lines MDA-MB-453 (Fig. 6A), HCC1937 (Fig. 6B) and HCC1143 (Fig. 6C). This effect, however, was again cell line dependent and compound specific. For example, enzalutamide significantly reduced migration in MDA-MB-453 cells but not in HCC1143 or HCC1937 cells, while reducing cell invasion in all three cell lines. In contrast to our findings in the AR-positive cell lines, enzalutamide did not affect migration or invasion in the AR-negative cell line Hs578t (Fig. 6D). Similarly, flutamide also reduced cell migration and invasion in
AR-positive cell lines MDA-MB-453 (Fig. 7A), HCC1937 (Fig. 7B) and HCC1143 (Fig. 7C) but not in the control AR-negative cells Hs578t (Fig. 7D).

\section{Prognostic significance of AR in breast cancer samples}

To evaluate the potential prognostic significance of AR expression in TNBC, we analysed a pooled gene expression database of 2091 patients. Clinical details of the patient cohorts included in the database are outlined in Table 2. In the total population of patients, high AR expression was found to be associated with good prognosis (Fig. 8A, HR=0.706, 95\% CI: 0.587-0.849, $\left.P=1.928 \times 10^{-4}\right)$. However, following separation of the total population of patients into their molecular subtype using the ssp2003 classifier (Sorlie et al. 2003), AR retained its positive prognostic significance in the luminal A group (Fig. 8B, HR=0.490, 95\% CI: 0.314-0.766, $P=0.001$, $n=812$ ). Conversely, in patients with basal tumours, AR was a marker of bad prognosis (Fig. 8C, HR=1.709, 95\% CI: 1.021-2.862, $P=0.039, n=273)$. In contrast, AR lacked a prognostic impact in the luminal $B$ and HER2-positive subtypes (data not shown).

Published by Bioscientifica Ltd 
Table 3 Gene expression changes induced by enzalutamide in MDA-MB-453 cells.

\begin{tabular}{|c|c|c|}
\hline Gene symbol & Gene name & Fold change \\
\hline FOS & $\begin{array}{l}\text { FBJ murine osteosarcoma viral } \\
\text { oncogene homolog }\end{array}$ & -2.85 \\
\hline JUN & Jun proto-oncogene & -3.83 \\
\hline ORM2 & Orosomucoid 2 & -2.66 \\
\hline SP1 & Sp1 transcription factor & -2.17 \\
\hline TMPRSS2 & Transmembrane protease, serine 2 & -2.42 \\
\hline
\end{tabular}

\section{Discussion}

To our knowledge, this is one of the largest preclinical studies to investigate the effects of the second-generation AR antagonist enzalutamide in TNBC cell lines. Unlike the first generation of AR antagonists, enzalutamide lacks AR agonistic activity (for review, see Ha \& Kim 2014) and, furthermore, has been reported to bind to AR with approximately eight-fold higher affinity than bicalutamide (Tran et al. 2009).

Although previous reports have investigated the anti-proliferative effects of anti-androgens on breast cancer cell line growth in vitro, until recently, most studies used only one cell line (Doane et al. 2006, Ni et al. 2011, Cochrane et al. 2014). While this manuscript was in preparation, Barton and coworkers reported the anti-proliferative effects of enzalutamide in four TNBC cell lines (Barton et al. 2015). In contrast, our study investigated the potential growth inhibitory effects of enzalutamide in 11 cell lines (eight of which were TN) and flutamide in four cell lines (all TN). Our results show that growth inhibition with both anti-androgens was dependent on the expression of the AR, i.e. high AR levels were associated with low $\mathrm{IC}_{50}$ values. Although such a finding might be expected, our study appears to be the first to report this observation.

Although frequently regarded as a homogeneous subgroup, it is important to stress that both TNBC and TNBC cell lines are highly heterogeneous (Lehmann et al. 2011, Santagata et al. 2014, and Table 1). Previously, most of the preclinical work investigating the anti-growth potential of enzalutamide on breast cancer cell lines focused on luminal AR (LAR) subtype, especially the MDA-MB-453 cell line. However, we here show that some cell lines not originally classified as LAR, expressed AR at the protein level and were responsive to AR-targeted therapy. Specifically, three basal-like (BL1) cell lines (HCC1143, HCC1937 and MDA-MB-468) and one mesenchymal stem-like (MSL) cell line (SUM159) were found to be
A
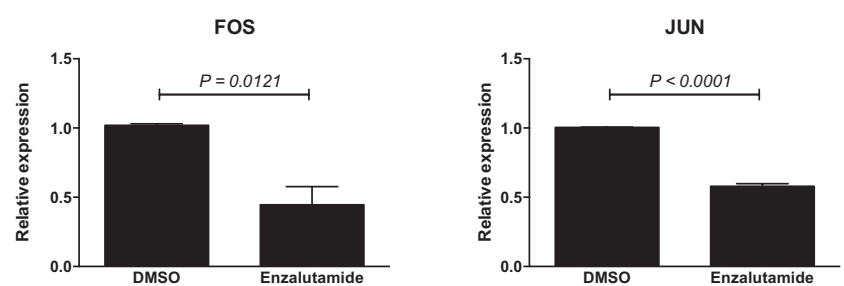

B

BT-20
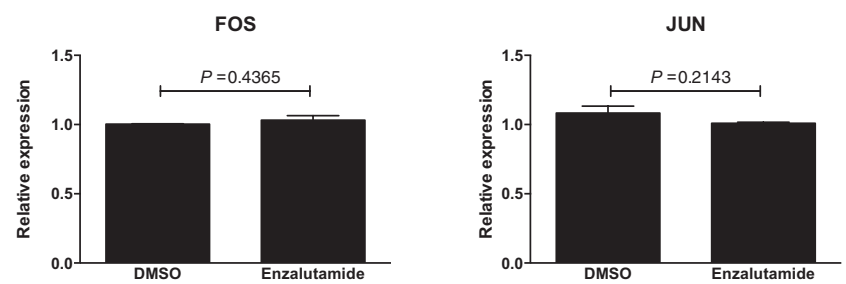

Figure 5

Effect of enzalutamide on gene expression. MDA-MB-453 (A) or BT-20 (B) cells were treated with enzalutamide $(10 \mu \mathrm{M})$ or vehicle control for $24 \mathrm{~h}$. mRNA was extracted and was reverse transcribed and analysed by real-time qRT-PCR using FOS- and JUN-specific primers. Data represents mean \pm S.E.M. values of three experiments.

sensitive to enzalutamide. We also showed that these AR-positive, non-LAR cells clustered separately from the AR-negative TN cells, based on the expression of 76 genes highly related to the LAR subtype of TNBC. Such results support the use of these cell lines as preclinical models of AR-positive TNBC. Our findings are thus in accordance with a recent report showing enzalutamidemediated growth inhibition in four different non-LAR TNBC cell lines of the mesenchymal-like MSL and BL2 subtypes (Barton et al. 2015).

Some differences exist between our results and those previously reported with enzalutamide in breast cancer cell lines. Thus, although MDA-MB-231 cells were not sensitive to enzalutamide in our study, a previous report found that growth of these cells was partially inhibited by enzalutamide (Barton et al. 2015). These different findings may relate to the different biological assay used to assess cell viability. It should also be stated that the Hs578t cell line, which is AR-negative and unresponsive to either flutamide or enzalutamide in our study, was previously reported to have mRNA expression of AR and to be partially responsive to bicalutamide (Lehmann et al. 2011). These apparently discordant results could be explained by the lack of concordance between transcript and corresponding protein expression, which was previously reported for steroid receptors

Published by Bioscientifica Ltd. 
A

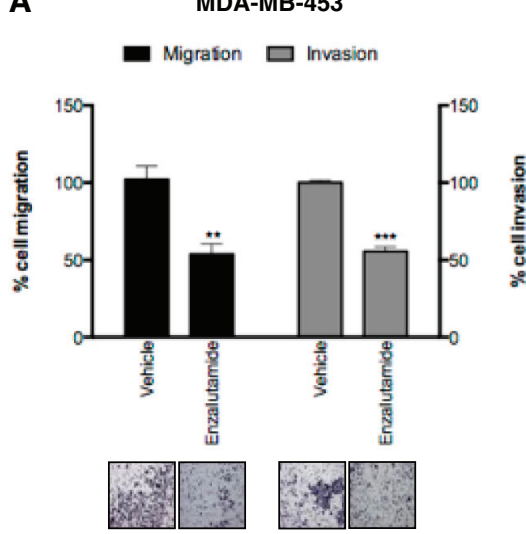

C

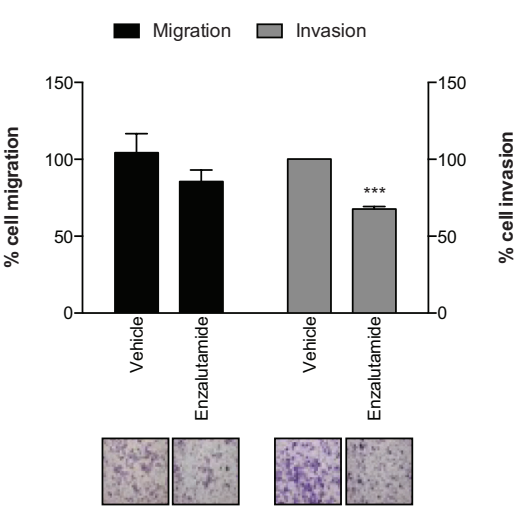

B
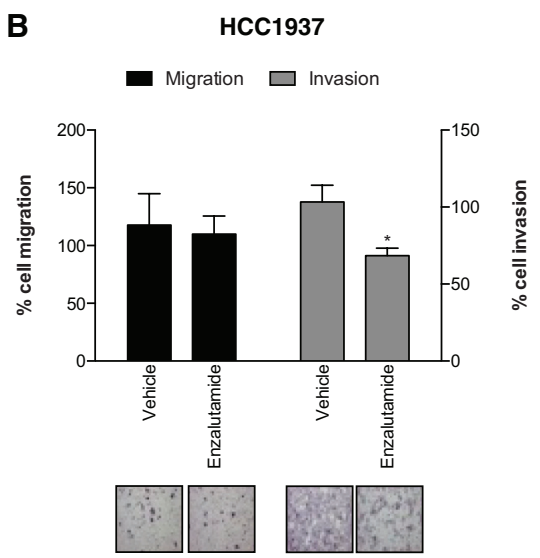

D

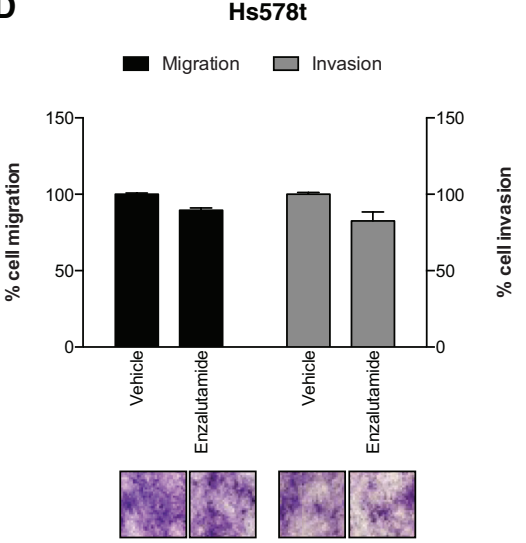

Figure 6

Effect of enzalutamide on TNBC cell migration and invasion. MDA-MB-453 (A), HCC1937 (B), HCC1143 (C) and Hs578t (D) cells were cultured in Matrigel-coated Boyden chambers or in control Boyden chambers without Matrigel coating, using fibroblast-conditioned media as a chemoattractant. Cells were treated with enzalutamide $(10 \mu \mathrm{M})$ or vehicle control for $72 \mathrm{~h}$ and then invaded/migrated cells were fixed, stained and counted. Data represent mean \pm S.E.M. values of three experiments. ${ }^{*} P<0.05, * * P<0.001$, $* * * P<0.0001$ compared with vehicle control (Student's $t$-test). A full colour version of this figure is available at http://dx.doi.org/10.1530/ ERC-16-0068.
(Caiazza et al. 2007, Vogel \& Marcotte 2012). A further potential reason for these discordances could be the different mechanisms of action between first- and second-generation anti-androgens.

In addition to the effects on cell proliferation, we also showed that both flutamide and enzalutamide inhibited cell invasion and migration of TNBC cells. The effect on these endpoints was again cell line and compound dependent. Thus, although both flutamide and enzalutamide significantly decreased migration in MDA-MB-453 cells, only flutamide impacted on this endpoint in HCC1937 and HCC1143 cells, whereas both compounds reduced cell invasion in all three AR-positive cell lines. Neither flutamide nor enzalutamide affected invasion or migration in the AR-negative cell line, Hs578t.

The involvement of AR signalling in metastasis and tumour invasiveness of non-prostate malignancies is still relatively unexplored. Previously, Castoria et al. (2013) reported that the anti-androgen bicalutamide blocked migration in several different cancer cell lines. However, in that study, TNBC cell lines were not investigated. In agreement with our findings,
Barton et al. recently reported that enzalutamide reduced migration and invasion of the TNBC cell line (BT549) (Barton et al. 2015).

In order to identify a putative mechanism to explain the effects of enzalutamide on the growth of AR-positive TNBC cells, we used a gene expression profiling tool to analyse a focused panel of genes in the AR signalling pathway. Five genes were down-regulated by enzalutamide treatment, including FOS and JUN (components of the early-response transcription factor AP-1) and the transcription factor SP-1. Both AP-1 and SP-1 are critical for the regulation of genes involved in proliferative signalling, replicative immortality, cell metabolism, as well as cell invasion and metastasis (Vesely et al. 2009, Beishline \& Azizkhan Clifford 2015). Both FOS and JUN were further validated by RT-PCR as being significantly down-regulated by enzalutamide, specifically in AR-positive cells. These results suggest that inhibition of transcriptional regulation through AP-1 (and possibly SP-1) could be involved in the anti-proliferative actions of enzalutamide in TNBC.

In order to establish a possible clinical role for AR in breast cancer, especially in the TN subtype, we evaluated

Published by Bioscientifica Ltd 
A

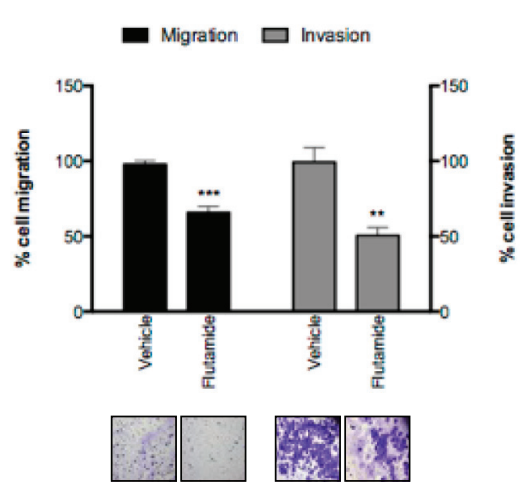

C

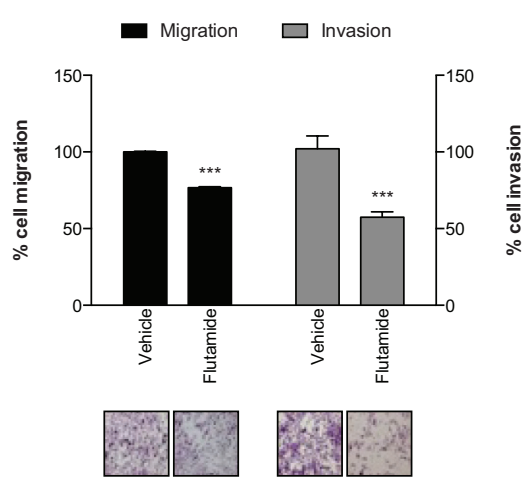

B

HCC1937

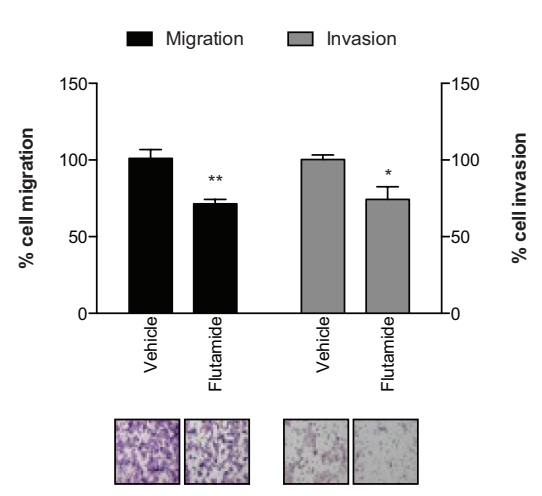

D

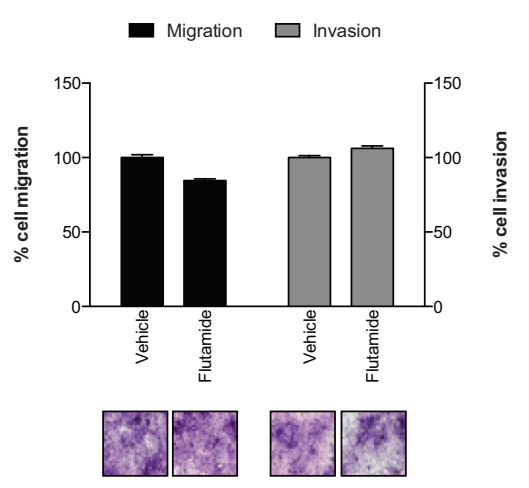

Figure 7

Effect of flutamide on TNBC cell migration and invasion. MDA-MB-453 (A), HCC1937 (B), HCC1143 (C) and Hs578t (D) cells were cultured in Matrigel-coated Boyden chambers or in control Boyden chambers without Matrigel coating, using fibroblast-conditioned media as a chemoattractant. Cells were treated with flutamide $(1 \mu \mathrm{M})$ or vehicle control for $72 \mathrm{~h}$ and then invaded/migrated cells were fixed, stained and counted. Data represent mean \pm S.E.M. values of three experiments. ${ }^{*} P<0.05, * * P<0.001$, $* * * P<0.0001$ compared with vehicle control (Student's $t$-test). A full colour version of this figure is available at http://dx.doi.org/10.1530/ ERC-16-0068. the prognostic potential of AR in a pooled database of 2091 patients (Madden et al. 2013). In agreement with a previous meta-analysis (Vera-Badillo et al. 2014), we found that high AR expression predicted a favourable outcome in the total population of patients. In contrast, in the subgroup of patients with basal disease (approximately 70-80\% of which are TN (Duffy et al. 2012)), the presence of AR was associated with poor outcome. A possible explanation for this difference between the total population and those with basal/TN disease is that AR inhibits growth of ER-positive breast cancer cells by antagonizing oestrogen receptor-induced signalling (Peters et al. 2009) but stimulates growth via an androgen-dependent mechanism in ER-negative and AR-positive cells (Doane et al. 2006, Hickey et al. 2012). A further possible explanation is that AR-positive TNBC may be less likely to benefit from chemotherapy than other forms of breast cancers (Masuda et al. 2013, Mayer et al. 2014).

It should be stated that conflicting results exist in the literature regarding the prognostic impact of AR in basal/TN breast cancer. In agreement with our finding,
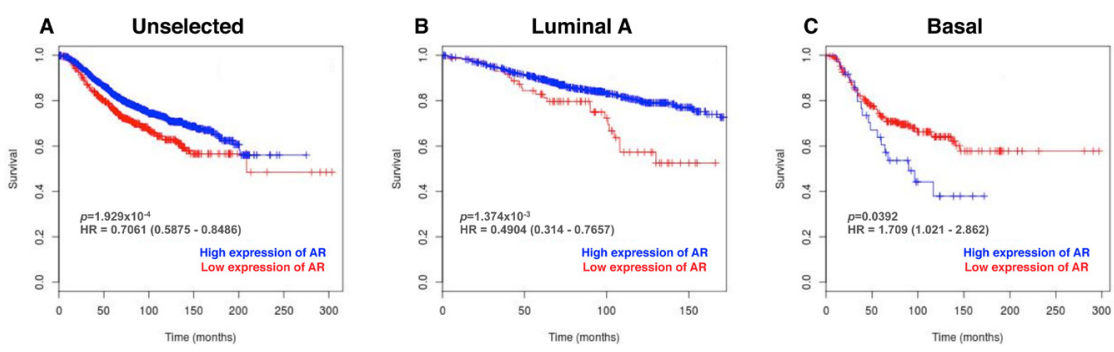

Figure 8

Prognostic effect of AR. Prognostic value of AR expression in breast cancer patients from the BreastMark database (Madden et al. 2013), using OS as the survival endpoint and 'low' as the expression cut-off. Kaplan-Meyer estimates for (A) unselected patients ( $n=2091, \mathrm{HR}=0.706$, $\left.P=1.928 \times 10^{-4}\right)$, (B) patients with luminal A subtype $\left(n=812, \mathrm{HR}=0.49, P=1.37 \times 10^{-3}\right)$ or (C) patients with basal subtype $(n=273, \mathrm{HR}=1.709$, $P=0.039$ ). Survival curves were compared with the Cox-Mantel log-rank test and the corresponding $P$-value is indicated. A full colour version of this figure is available at http://dx.doi. org/10.1530/ERC-16-0068. 
Hu et al. (2011) reported that high AR levels predicted poor patient outcome. In contrast, a recent meta-analysis found that increased AR expression predicted good outcome in this subset of breast cancer patients ( $\mathrm{Qu}$ et al. 2013). Another confounding factor is the fact that basal and $\mathrm{TN}$ breast cancer are not synonymous, and standardised criteria for defining both subgroups have not been defined.

In conclusion, we have shown that two structurally different anti-androgens can inhibit cell growth, invasion and migration in AR-positive TNBC cell lines. Our finding should inform ongoing clinical trials investigating the targeting of $\mathrm{AR}$ in patients with TNBC. Indeed, promising preliminary results from these trials have been reported in patients with advanced AR-positive TNBC (Cortes et al. 2015, Traina et al. 2015). Thus, in a phase II study, administration of enzalutamide to AR-positive patients who were also positive for a specific androgen-driven gene signature (PREDICT AR) was reported to result in a superior outcome, compared with patients negative for this signature (Cortes et al. 2015). As anti-androgens are already widely used to treat metastatic prostate cancer, repurposing them for use in TNBC could proceed rapidly. Finally, as the AR is expressed in several different types of cancer (Munoz et al. 2014), targeting with androgen antagonists may have wide application in cancer treatment.

\section{Supplementary data}

This is linked to the online version of the paper at http://dx.doi.org/10.1530/ ERC-16-0068

\section{Declaration of interest}

J C has received an educational grant from Astellas Pharma Ireland in 2014. The authors would like to confirm that there are no other known conflicts of interest associated with this publication for all other co-authors, and there has been no significant financial support for this work that could have influenced its outcome.

\section{Funding}

The authors would like to thank Science Foundation Ireland, Strategic Research Cluster Award (08/SRC/B1410) to Molecular Therapeutics for Cancer Ireland ( $\mathrm{MTCl}) /$ National Cancer Research Centre in Ireland ( $\mathrm{NCRCI}$, the Cancer Clinical Research Trust and the BREAST-PREDICT (CCRC13GAL) programme of the Irish Cancer Society for funding this work. FC is currently supported by a Newman Fellowship awarded by the UCD Foundation funded by a donation from Merck Serono.

\section{Author contribution}

FC, AM and MJD designed the study and developed the methodology. FC, AM, SFM, NCS and EJR performed the experimental procedures and analysed the data. FC, AM and MJD prepared the manuscript. NOD, JC, SFM and MJD contributed reagents, materials and analysis tools.

\section{Acknowledgements}

The authors would like to thank Dr Maria Prencipe and Prof William Watson (University College Dublin) for providing support and materials.

\section{References}

Barton VN, D'Amato NC, Gordon MA, Lind HT, Spoelstra NS, Babbs BL, Heinz RE, Elias A, Jedlicka P, Jacobsen BM, et al. 2015 Multiple molecular subtypes of triple-negative breast cancer critically rely on androgen receptor and respond to enzalutamide in vivo. Molecular Cancer Therapeutics 14 769-778. (doi:10.1158/1535-7163.MCT-14-0926)

Beishline K \& Azizkhan Clifford J 2015 Sp1 and the 'hallmarks of cancer'. FEBS Journal 282 224-258. (doi:10.1111/febs.13148)

Cai Z, Chattopadhyay N, Liu WJ, Chan C, Pignol J-P \& Reilly RM 2011 Optimized digital counting colonies of clonogenic assays using Image software and customized macros: comparison with manual counting. International Journal of Radiation Biology 87 1135-1146. (doi:10.3109/09553002.2011.622033)

Caiazza F, Galluzzo P, Lorenzetti S \& Marino M 2007 17Beta-estradiol induces ERbeta up-regulation via p38/MAPK activation in colon cancer cells. Biochemical and Biophysical Research Communications 359 102-107. (doi:10.1016/j.bbrc.2007.05.059)

Caiazza F, McGowan PM, Mullooly M, Murray A, Synnott N, O'Donovan N, Flanagan L, Tape CJ, Murphy G, Crown J, et al. 2015 Targeting ADAM-17 with an inhibitory monoclonal antibody has antitumour effects in triple-negative breast cancer cells. British Journal of Cancer 112 1895-1903. (doi:10.1038/bjc.2015.163)

Castoria G, Giovannelli P, Di Donato M, Hayashi R, Arra C, Appella E, Auricchio F \& Migliaccio A 2013 Targeting androgen receptor/Src complex impairs the aggressive phenotype of human fibrosarcoma cells. PloS One 8 e76899. (doi:10.1371/journal.pone.0076899)

Chen S-Y, Cai C, Fisher CJ, Zheng Z, Omwancha J, Hsieh C-L \& Shemshedini L 2006 c-Jun enhancement of androgen receptor transactivation is associated with prostate cancer cell proliferation. Oncogene 25 7212-7223. (doi:10.1038/sj.onc.1209705)

Cochrane DR, Bernales S, Jacobsen BM, Cittelly DM, Howe EN, D Amato NC, Spoelstra NS, Edgerton SM, Jean A, Guerrero J, et al. 2014 Role of the Androgen Receptor in Breast Cancer and Preclinical Analysis of Enzalutamide. Breast Cancer Research 16 R7. (doi:10.1186/bcr3599)

Collins LC, Cole KS, Marotti JD, Hu R, Schnitt SJ \& Tamimi RM 2011 Androgen receptor expression in breast cancer in relation to molecular phenotype: results from the Nurses' Health Study. Modern Pathology 24 924-931. (doi:10.1038/modpathol.2011.54)

Cortes J, Crown J, Awada A, Schmid P, Gianni L, Garcia-Estevez L, Martinez-Janez N, Chan S, Steinberg JL, Blaney M, et al. 20151802 Overall survival (OS) from the phase 2 study of enzalutamide (ENZA), an androgen receptor (AR) signaling inhibitor, in AR+ advanced triplenegative breast cancer (aTNBC). European Journal of Cancer $\mathbf{5 1}$ (Supplement 3) S265. (doi:10.1016/s0959-8049(16)30756-0)

Doane AS, Danso M, Lal P, Donaton M, Zhang L, Hudis C \& Gerald WL 2006 An estrogen receptor-negative breast cancer subset characterized by a hormonally regulated transcriptional program and response to androgen. Oncogene 25 3994-4008. (doi:10.1038/ sj.onc.1209415)

Duffy MJ, McGowan PM \& Crown J 2012 Targeted therapy for triplenegative breast cancer: where are we? International Journal of Cancer 131 2471-2477. (doi:10.1002/ijc.27632)

Farmer P, Bonnefoi H, Becette V, Tubiana-Hulin M, Fumoleau P, Larsimont D, Macgrogan G, Bergh J, Cameron D, Goldstein D, et al. 2005 Identification of molecular apocrine breast tumours by microarray analysis. Oncogene 24 4660-4671. (doi:10.1038/ sj.onc.1208561)

Gasparini P, Fassan M, Cascione L, Guler G, Balci S, Irkkan C, Paisie C, Lovat F, Morrison C, Zhang J, et al. 2014 Androgen receptor status is 
a prognostic marker in non-basal triple negative breast cancers and determines novel therapeutic options. PloS One 9 e88525. (doi:10.1371/journal.pone.0088525)

Gucalp A \& Traina TA 2010 Triple-negative breast cancer. Cancer Journal 16 62-65. (doi:10.1097/PPO.0b013e3181ce4ae1)

Gucalp A, Tolaney S, Isakoff SJ, Ingle JN, Liu MC, Carey LA, Blackwell K, Rugo H, Nabell L, Forero A, et al. 2013 Phase II trial of bicalutamide in patients with androgen receptor-positive, estrogen receptornegative metastatic breast cancer. Clinical Cancer Research 19 55055512. (doi:10.1158/1078-0432.CCR-12-3327)

Ha Y-S \& Kim IY 2014 Enzalutamide: looking back at its preclinical discovery. Expert Opinion on Drug Discovery 9 837-845. (doi:10.1517/ 17460441.2014.918947)

Hickey TE, Robinson JLL, Carroll JS \& Tilley WD 2012 Minireview: the androgen receptor in breast tissues: growth inhibitor, tumor suppressor, oncogene? Molecular Endocrinology 26 1252-1267. (doi:10.1210/me.2012-1107)

Hu R, Dawood S, Holmes MD, Collins LC, Schnitt SJ, Cole K, Marotti JD, Hankinson SE, Colditz GA \& Tamimi RM 2011 Androgen receptor expression and breast cancer survival in postmenopausal women. Clinical Cancer Research 17 1867-1874. (doi:10.1158/10780432.CCR-10-2021)

Kao J, Salari K, Bocanegra M, Choi Y-L, Girard L, Gandhi J, Kwei KA, Hernandez-Boussard T, Wang P, Gazdar AF, et al. 2009 Molecular profiling of breast cancer cell lines defines relevant tumor models and provides a resource for cancer gene discovery. Plos One $\mathbf{4}$ e6146. (doi:10.1371/journal.pone.0006146)

Kotsopoulos J \& Narod SA 2012 Androgens and breast cancer. Steroids 77 1-9. (doi:10.1016/j.steroids.2011.10.002)

Lehmann BD, Bauer JA, Chen X, Sanders ME, Chakravarthy AB, Shyr Y \& Pietenpol JA 2011 Identification of human triple-negative breast cancer subtypes and preclinical models for selection of targeted therapies. Journal of Clinical Investigation 121 2750-2767. (doi:10.1172/JCI45014)

Madden SF, Clarke C, Gaule P, Aherne ST, O'Donovan N, Clynes M, Crown J \& Gallagher WM 2013 BreastMark: an integrated approach to mining publicly available transcriptomic datasets relating to breast cancer outcome. Breast Cancer Research 15 R52. (doi:10.1186/bcr3444)

Masuda H, Baggerly KA, Wang Y, Zhang Y, Gonzalez-Angulo AM, Meric-Bernstam F, Valero V, Lehmann BD, Pietenpol JA, Hortobagyi GN, et al. 2013 Differential response to neoadjuvant chemotherapy among 7 triple-negative breast cancer molecular subtypes. Clinical Cancer Research 19 5533-5540. (doi:10.1158/1078-0432.CCR-13-0799)

Mayer IA, Abramson VG, Lehmann BD \& Pietenpol JA 2014 New strategies for triple-negative breast cancer - deciphering the heterogeneity. Clinical Cancer Research 20 782-790. (doi:10.1158/1078-0432.CCR-13-0583)

McNamara KM, Yoda T, Miki Y, Chanplakorn N, Wongwaisayawan S, Incharoen P, Kongdan Y, Wang L, Takagi K, Mayu T, et al. 2013 Androgenic pathway in triple negative invasive ductal tumors: its correlation with tumor cell proliferation. Cancer Science 104 639-646. (doi:10.1111/cas.12121)

Munoz J, Wheler JJ \& Kurzrock R 2015 Androgen receptors beyond prostate cancer: an old marker as a new target. Oncotarget 6 592-603. (doi:10.18632/oncotarget.2831).

Neve RM, Chin K, Fridlyand J, Yeh J, Baehner FL, Fevr T, Clark L, Bayani N, Coppe J-P, Tong F, et al. 2006 A collection of breast cancer cell lines for the study of functionally distinct cancer subtypes. Cancer Cell 10 515-527. (doi:10.1016/j.ccr.2006.10.008)

Ni M, Chen Y, Lim E, Wimberly H, Bailey ST, Imai Y, Rimm DL, Liu XS \& Brown M 2011 Targeting androgen receptor in estrogen receptornegative breast cancer. Cancer Cell 20 119-131. (doi:10.1016/ j.ccr.2011.05.026)
Park S, Koo J, Park HS, Kim J-H, Choi S-Y, Lee JH, Park B-W \& Lee KS 2010 Expression of androgen receptors in primary breast cancer. Annals of Oncology 21 488-492. (doi:10.1093/annonc/mdp510)

Parker JS, Mullins M, Cheang MCU, Leung S, Voduc D, Vickery T, Davies S, Fauron C, He X, Hu Z, et al. 2009 Supervised risk predictor of breast cancer based on intrinsic subtypes. Journal of Clinical Oncology 27 1160-1167. (doi:10.1200/JCO.2008.18.1370)

Peters AA, Buchanan G, Ricciardelli C, Bianco-Miotto T, Centenera MM, Harris JM, Jindal S, Segara D, Jia L, Moore NL, et al. 2009 Androgen receptor inhibits estrogen receptor-alpha activity and is prognostic in breast cancer. Cancer Research 69 6131-6140. (doi:10.1158/00085472.CAN-09-0452)

Proverbs-Singh T, Feldman JL, Morris MJ, Autio KA \& Traina TA 2015 Targeting the androgen receptor in prostate and breast cancer: several new agents in development. Endocrine-Related Cancer 22 R87-R106. (doi:10.1530/ERC-14-0543)

Qu Q, Mao Y, Fei X-C \& Shen K-W 2013 The impact of androgen receptor expression on breast cancer survival: a retrospective study and metaanalysis. PloS ONE 8 e82650. (doi:10.1371/journal.pone.0082650)

Risbridger GP, Davis ID, Birrell SN \& Tilley WD 2010 Breast and prostate cancer: more similar than different. Nature Reviews Cancer $\mathbf{1 0}$ 205-212. (doi:10.1038/nrc2795)

Safarpour D \& Tavassoli FA 2014 A Targetable androgen receptor-positive breast cancer subtype hidden among the triple-negative cancers. Archives of Pathology \& Laboratory Medicine. 139 612-617. (doi:10.5858/arpa.2014-0122-RA)

Santagata S, Thakkar A, Ergonul A, Wang B, Woo T, Hu R, Harrell JC, McNamara G, Schwede M, Culhane AC, et al. 2014 Taxonomy of breast cancer based on normal cell phenotype predicts outcome. Journal of Clinical Investigation 124 859-870. (doi:10.1172/JCI70941)

Shah PD, Gucalp A \& Traina TA 2013 The role of the androgen receptor in triple-negative breast cancer. Women's Health 9 351-360. (doi:10.2217/whe.13.33)

Sorlie T, Tibshirani R, Parker J, Hastie T, Marron JS, Nobel A, Deng S, Johnsen H, Pesich R, Geisler S, et al. 2003 Repeated observation of breast tumor subtypes in independent gene expression data sets. PNAS 100 8418-8423. (doi:10.1073/pnas.0932692100)

Traina TA, Miller K, Yardley DA, O'Shaughnessy JA, Javier C, Avada A, Kelly CM, Trudeau ME, Schmid P, Gianni L, et al. 2015 Results from a phase 2 study of enzalutamide (ENZA), an androgen receptor (AR) inhibitor, in advanced AR+ triple-negative breast cancer (TNBC). Journal of Clinical Oncology 33 (Supplement 15) abstract 1003. (available at: http://meeting.ascopubs.org/cgi/content/ abstract/33/15_suppl/1003)

Tran C, Ouk S, Clegg NJ, Chen Y, Watson PA, Arora V, Wongvipat J, Smith-Jones PM, Yoo D, Kwon A, et al. 2009 Development of a second-generation antiandrogen for treatment of advanced prostate cancer. 324 787-790. (doi:10.1126/science.1168175)

Vera-Badillo FE, Templeton AJ, de Gouveia P, Diaz-Padilla I, Bedard PL, Al-Mubarak M, Seruga B, Tannock IF, Ocaña A \& Amir E 2014 Androgen receptor expression and outcomes in early breast cancer: a systematic review and meta-analysis. Journal of the National Cancer Institute 106 djt319. (doi:10.1093/jnci/djt319)

Vesely PW, Staber PB, Hoefler G \& Kenner L 2009 Translational regulation mechanisms of AP-1 proteins. Mutation Research 682 7-12. (doi:10.1016/j.mrrev.2009.01.001)

Vogel C \& Marcotte EM 2012 Insights into the regulation of protein abundance from proteomic and transcriptomic analyses. Nature Reviews Genetics 13 227-232. (doi:10.1038/nrg3185)

Weinstein JN, Myers TG, O'Connor PM, Friend SH, Fornace AJ, Kohn KW, Fojo T, Bates SE, Rubinstein LV, Anderson NL, et al. 1997 An information-intensive approach to the molecular pharmacology of cancer. Science 275 343-349. (doi:10.1126/science.275.5298.343)

Received in final form 24 February 2016

Accepted 1 March 2016

Accepted Preprint published online 1 March 2016

Published by Bioscientifica Ltc. http://erc.endocrinology-journals.org

DOI: 10.1530/ERC-16-0068
(C) 2016 Society for Endocrinology Printed in Great Britain 